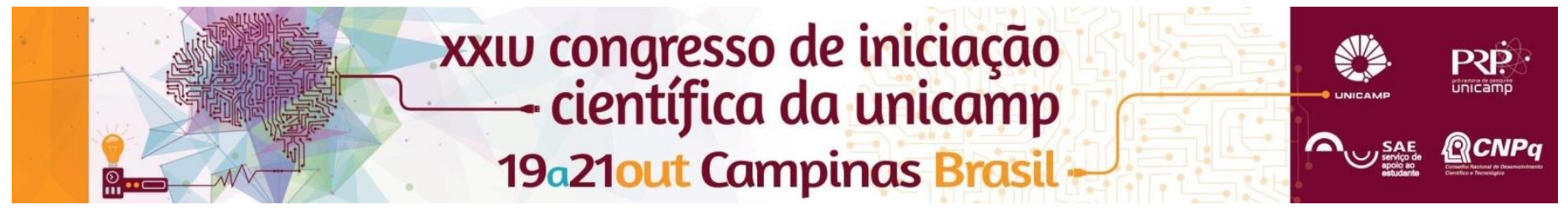

\title{
Influência do tecido adiposo perivascular nas complicações vasculares de camundongos com deficiência do receptor de LDL: Efeitos do tratamento in vivo com sinvastatina.
}

\author{
Natali Baltieri (IC), Daniele M. Guizoni (PQ), Ana P. Davel (PQ)
}

\begin{abstract}
Resumo
A fisiopatologia da doença aterosclerótica está associada à redução na síntese e/ou biodisponibilidade de óxido nítrico (NO) derivado do endotélio, assim como, ao aumento da síntese de fatores pró-inflamatórios locais. A sinvastatina é um fármaco hipolipidêmico que pode apresentar ação anti-inflamatória, além de melhorar a sensibilidade à insulina e a produção de NO. Recentemente, o tecido adiposo perivascular (PVAT) tem sido descrito como um importante regulador da função endotelial e fonte de citocinas. Porém, ainda não se sabe se o PVAT influencia na disfunção endotelial consequente à hipercolesterolemia, assim como nos efeitos das estatinas. $O$ objetivo deste estudo foi avaliar o papel do PVAT na disfunção endotelial, na produção de NO e de fatores inflamatórios em modelo experimental de hipercolesterolemia familiar, assim como investigar o possível efeito benéfico do tratamento in vivo com sinvastatina sobre estes parâmetros.
\end{abstract}

Palavras-chave: Aterosclerose, tecido adiposo perivascular, óxido nítrico, sinvastatina.

\section{Introdução}

A doença isquêmica do coração é a principal causa de morte nos países em desenvolvimento, e tem como agente etiológico mais comum a aterosclerose, desencadeada pela disfunção endotelial associada a dislipidemias, que prejudica o relaxamento vascular e induz ao processo inflamatório. Camundongos knockout para o receptor de LDL (KO) constituem um modelo experimental da hipercolesterolemia familiar (HF) e desenvolvem disfunção endotelial associada à redução na síntese e/ou biodisponibilidade de óxido nítrico (NO), e aumento de fatores pró-inflamatórios. $O$ tecido adiposo perivascular (PVAT) participa do controle local dos níveis de $\mathrm{NO}$ e do estado inflamatório vascular. Porém, pouco se sabe sobre o seu papel na HF.

A sinvastatina (Sinva) é um fármaco da família das estatinas bastante utilizada no tratamento de dislipidemias. Ela possui efeitos pleiotrópicos à diminuição sérica de colesterol incluindo ação antiinflamatória, melhora da sensibilidade à insulina e estimulação da produção de NO. Assim, no presente estudo levantamos a hipótese de que o tratamento com Sinva poderia ser benéfico para a função endotelial de animais $\mathrm{KO}$, via modulação da atividade do PVAT.

\section{Resultados e Discussão}

Foram utilizados camundongos C57BI6/J selvagens (WT) e KO tratados ou não com Sinva. Os valores séricos de colesterol $(\mathrm{WT}=85 \pm 5$, WT+Sinva $=$ $\left.88 \pm 10, K O=262 \pm 14^{*}, K O+S i n v a=234 \pm 13^{*} \mathrm{mg} / \mathrm{dL}\right)$ e triglicérides $\left(\mathrm{WT}=54 \pm 4, \mathrm{WT}+\mathrm{Sinva}=50 \pm 6, \mathrm{KO}=145 \pm 12^{*}\right.$, $\mathrm{KO}+\operatorname{Sinva}=156 \pm 13^{*} \mathrm{mg} / \mathrm{dL}$ ) foram aumentados no grupo $\mathrm{KO}(\mathrm{P}<0,05:$ * vs. WT), sem efeito significativo do tratamento com Sinva. Isso mostra que animais KO apresentaram dislipidemia, que não foi alterada pelo tratamento com Sinva no tempo estabelecido.

Em segmentos de aorta isolada, observou-se que, na ausência de PVAT, o relaxamento dependente do endotélio induzido por acetilcolina e por insulina são prejudicados nos animais KO. Ambas as respostas de relaxamento são restauradas pelo tratamento com Sinva ou pela presença do PVAT. De acordo, houve aumento da expressão da sintase do NO (eNOS) no PVAT, ao mesmo tempo que a expressão desta enzima foi reduzida na aorta dos animais KO (Figura 1). O tratamento com Sinva reverte o aumento da eNOS no PVAT do grupo KO. Desta maneira, o aumento da eNOS no PVAT pode ser um mecanismo compensatório à produção deficiente de NO pelo endotélio da aorta, e assim, recuperar a capacidade vasorrelaxante. Não foram observadas diferenças na resposta de relaxamento ao nitroprussiato de sódio, doador de NO, o que sugere uma responssividade vascular normal ao NO. A ativação da via de sinalização IRS1/PI3-K/Akt pela insulina induz a ativação da eNOS e consequente produção de NO. O padrão de expressão destas proteínas no PVAT não foi modificado nos animais KO em comparação ao grupo WT, nem pelo pelo tratamento com Sinva. No entanto, houve um aumento significativo $(P<0.05)$ dos níveis séricos da citocina próinflamatória TNF-a em animais $\mathrm{KO}$, quando comparados ao grupo WT (+100\%), o que foi revertido pelo tratamento com Sinva. Não houve modificação dos níveis séricos de IL-6 ou de adiponectina entre os grupos.
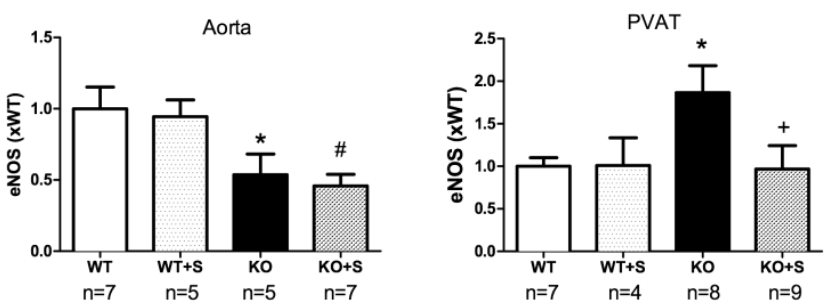

Figura 1. Expressão proteica da eNOS em aorta e tecido adiposo perivascular (PVAT) de camundongos selvagens (WT) e knockout para o receptor de LDL (KO) tratados ou não com sinvastatina (S) por 4 semanas. Dados expressos como média \pm EPM. ANOVA 2-vias, $\mathrm{p}<0,05:{ }^{*}$ vs. WT; ${ }^{+}$vs. $\mathrm{KO}{ }^{\#}$ vs. WT+S.

\section{Conclusões}

Os dados sugerem que o PVAT apresenta papel protetor sobre as respostas vasorrelaxantes dependentes do endotélio em modelo experimental de HF. A ação terapêutica da Sinva sobre a função vascular nestes animais foi associada à redução dos níveis circulantes de TNF-a, mas independente do papel do PVAT e dos níveis séricos de colesterol e triglicérides.

\section{Agradecimentos}

Instituição de fomento: FAPESP. 